\title{
Commentary: Antifibrotics in COVID-19 Lung Disease: Let Us Stay Focused
}

\author{
Soroush Seifirad* and Lance Alquran \\ Department of Internal Medicine, Hackensack Meridian Health Mountainside Medical Center, Montclair, NJ, United States
}

Keywords: COVID-19, antifibrotics, fibrosis, ARDS, Pirfenidone

\section{A Commentary on}

Antifibrotics in COVID-19 Lung Disease: Let Us Stay Focused

by Chaudhary, S., Natt, B., Bime, C., Knox, K. S., and Glassberg, M. K. (2020). Front. Med. 7:539.

doi: 10.3389/fmed.2020.00539

\section{INTRODUCTION}

We read with a particular interest the article entitled "Antifibrotics in COVID-19 Lung Disease: Let Us Stay Focused" published by Chaudhary et al. in your prestigious journal, where the authors discussed their point of view regarding the application of approved antifibrotics in the treatment of COVID-19 patients (1). Dr. Chaudhary et al. believe that since some post-viral ARDS patients recover with only mild residual pulmonary deficits, interventions to prevent mild abnormalities would be unnecessary. They also argued that progressive fibrosis is not an important characteristic in ARDS related to respiratory infections and viral pneumonias. In contrast to these statements, the authors admit it is too early to reliably define the long-term outcomes in patients recovering from a severe COVID-19 infection.

They opposed the hypothesis of applicability of approved IPF treatments in COVID-19 patients and commented against the study of anti-fibrotic agents such as Pirfenidone, in the treatment of COVID-19 patients. The authors believe that the relationship between COVID-19 and IPF is nonsense, and hence stated that Pirfenidone trials are a waste of resources. Nevertheless, loss of similarity between IPF and COVID-19 as stated by the authors does not necessarily mean that Pirfenidone will not be helpful in the treatment of patients with COVID-19.

\section{DISCUSSION}

As I, Soroush Seifirad, discussed previously in my published article, there are several rational pathways in pathogenesis of COVID-19 that will be addressed by treatment with Pirfenidone (2). Having a deep understanding of the mechanism of action of a potential medication is essential in suggesting a new treatment. We should model both the disease and the drug mechanism of action, irrelevant of their current application, and recommend novel treatments accordingly $(3,4)$. Indeed, a large number of currently approved medications in medicine have been proposed for other totally irrelevant disorders; among them are Amantadine, Sildenafil, and Carbamazepine (5).

The reason behind suggesting Pirfenidone is not simply the similarity of COVID-19 ARDS/Fibrosis and IPF; but the pathogenesis of COVID-19 disease; it's receptor, and the mechanism of action of Pirfenidone. In line with our hypothesis, a recent in-silico drug repurposing study suggested promising modeling results for the combination of Pirfenidone and melatonin as a potential treatment to diminish SARS-CoV-2 infection progression and respiratory distress 


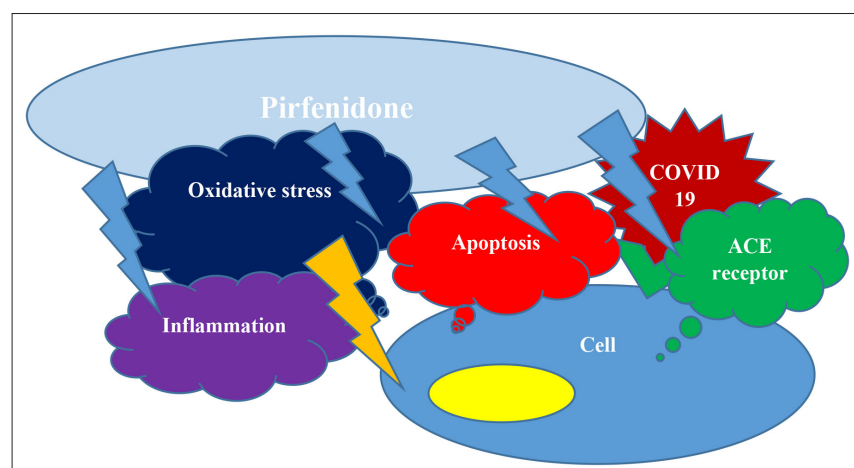

FIGURE 1 | Pirfenidone can hinder apoptosis, may down regulate ACE receptors expression, could decrease inflammation and decrease oxidative stress and hence protect from COVID19 cellular entrance and cytokine storm concurrently.

due to cytokine storm (6). Nevertheless, at the end of the day, only clinical trials are going to determine if this hypothetical treatment would work. A series of clinical trials are already being conducted, among them are a Chinese multicenter clinical trial sponsored by Huilan Zhang (Study Identifier: NCT04282902), an American trial by PureTech on LYT-100 (deupirfenidone) and a Spanish study (NCT04607928).

COVID-19 patients suffer from severe inflammation, cytokine storms, oxidative stress, reactive oxygen species damage, and increased permeability of vascular bed. These mechanisms are responsible for the development of ARDS and multi-organ damage (2, 7-9). We do agree with the respected authors that it is premature to consider fibrosis after COVID-19 lung disease irreversible and similar to IPF. With no doubt, we need more data and follow up studies to understand characteristics of COVID19 lung disease, its sequels and reversibility of fibrosis (1). Nevertheless, as we will discuss this fact does not necessarily contradict applicability of antifibrotics such as Pirfenidone in the treatment of COVID-19 patients.

\section{REFERENCES}

1. Chaudhary S, Natt B, Bime C, Knox KS, Glassberg MK. Antifibrotics in COVID-19 lung disease: let us stay focused. Front Med. (2020) 7:539. doi: 10.3389/fmed.2020.00539

2. Seifirad S. Pirfenidone: A novel hypothetical treatment for COVID-19. Med Hypotheses. (2020) 144:110005. doi: 10.1016/j.mehy.2020.110005

3. Seifirad S, Keshavarz A, Taslimi S, Aran S, Abbasi H, Ghaffari A. Effect of pirfenidone on pulmonary fibrosis due to paraquat poisoning in rats. Clin Toxicol. (2012) 50:754-8. doi: 10.3109/15563650.2012.718783

4. Seifirad S. Pirfenidone could decrease paraquat-induced pulmonary fibrosis in rats. Tzu Chi Med J. (2013) 25:130. doi: 10.1016/j.tcmj.2013.03.002

5. Seifirad S, Haghpanah V. Inappropriate modeling of chronic and complex disorders: How to reconsider the approach in the context of predictive, preventive and personalized medicine, and translational medicine. EPMA J. (2019) 10:195-209. doi: 10.1007/s13167-019-00176-Z

6. Artigas L, Coma M, Matos-Filipe P, Aguirre-Plans J, Farres J, Valls R, et al. In-silico drug repurposing study predicts the combination of pirfenidone and melatonin as a promising candidate therapy to reduce SARS-CoV-2 infection
The anti-inflammatory characteristics of Pirfenidone have been reported in several published articles $(3,4)$. Pirfenidone decreases TNF- $\alpha$ secretion and plenty of other inflammatory cytokines (10-13). Pirfenidone also blocks NLRP3 inflammasome activation, it ameliorates lipopolysaccharide induced inflammation and fibrosis $(14,15)$. Pirfenidone strongly inhibits TGF- $\beta$ 1-induced fibronectin synthesis $(16,17)$. It also down-regulates the profibrotic gene expression, and collagen secretion $(16,18)$. Pirfenidone prevents collagen I fibril formation, and up regulates RGS2 which can potentially lead to amelioration of pulmonary fibrosis (19-22). Pirfenidone also inhibits NADPH dependent lipid peroxidation (23). The antioxidant character of Pirfenidone suggests its capability for the treatment of hyperimmune response $(3,24)$. Pirfenidone could decrease apoptosis and as a result combat sever viral inflammation, ARDS, and ARDS fibrosis $(25,26)$. Finally, it has been demonstrated that Pirfenidone inhibits the AT1R/p38 MAPK pathway, decreases angiotensin II, and angiotensin II type 1 receptor, as well as angiotensin-converting enzyme (ACE) expression, which will both protect cells from developing fibrosis (LXR- $\alpha$ ), and limit entrance of the COVID-19-SARS virus into cells by decreasing ACE receptors (2, 27, 28).

In conclusion, as we discussed above, Pirfenidone may protect pneumocytes and other cells from COVID-19 invasion and cytokine storm simultaneously by inhibiting apoptosis, downregulating ACE receptors expression, subsiding inflammation by several mechanisms, and improving oxidative stress (Figure 1); (2). We would like to respectfully oppose their statement and support clinical trials of Pirfenidone, particularly for moderate to severe COVID-19 patients.

\section{AUTHOR CONTRIBUTIONS}

SS: idea and drafting article and final approval. LA: drafting article, English revision, and final approval. All authors contributed to the article and approved the submitted version.

progression and respiratory distress caused by cytokine storm. PLoS ONE. (2020) 15:e0240149. doi: 10.1371/journal.pone.0240149

7. Williams A, Alquran L, Khan U, Bambrick-Santoyo G, Goveas R. Atypical Presentation of COVID-19 Leading to ARDS. Case Rep Infect Dis. (2020) 2020:1070249. doi: 10.1155/2020/1070249

8. Tahvildari A, Arbabi M, Farsi Y, Jamshidi P, Hasanzadeh S, Calcagno TM, et al. Clinical features, diagnosis, and treatment of COVID-19 in hospitalized patients: a systematic review of case reports and case series. Front Med. (2020) 7:231. doi: 10.3389/fmed.2020.00231

9. Nasiri MJ, Haddadi S, Tahvildari A, Farsi Y, Arbabi M, Hasanzadeh $\mathrm{S}$, et al. COVID-19 clinical characteristics, and sex-specific risk of mortality: systematic review and meta-analysis. Front Med. (2020) 7:459. doi: 10.3389/fmed.2020.00459

10. Cain WC, Stuart RW, Lefkowitz DL, Starnes JD, Margolin S, Lefkowitz SS. Inhibition of tumor necrosis factor and subsequent endotoxin shock by pirfenidone. Int J Immunopharmacol. (1998) 20:685-95. doi: 10.1016/s0192-0561(98)00042-3

11. Poulin Braim AE, MacDonald MH, Bruss ML, Grattendick KJ, Giri SN, Margolin SB. Effects of intravenous administration of pirfenidone on horses 
with experimentally induced endotoxemia. Am J Vet Res. (2009) 70:103142. doi: 10.2460/ajvr.70.8.1031

12. Shi $\mathrm{Q}$, Liu $\mathrm{X}, \mathrm{Bai} \mathrm{Y}$, Cui $\mathrm{C}, \mathrm{Li} \mathrm{J}$, Li $\mathrm{Y}$, et al. In vitro effects of pirfenidone on cardiac fibroblasts: proliferation, myofibroblast differentiation, migration and cytokine secretion. PLOS ONE. (2011) 6:e28134. doi: 10.1371/journal.pone.0028134

13. Hale ML, Margolin SB, Krakauer T, Roy CJ, Stiles BG. Pirfenidone blocks the in vitro and in vivo effects of staphylococcal enterotoxin B. Infect Immunity. (2002) 70:2989-94. doi: 10.1128/iai.70.6.2989-2994.2002

14. Li Y, Li H, Liu S, Pan P, Su X, Tan H, et al. Pirfenidone ameliorates lipopolysaccharide-induced pulmonary inflammation and fibrosis by blocking NLRP3 inflammasome activation. Mol Immunol. (2018) 99:134-44. doi: 10.1016/j.molimm.2018.05.003

15. Wang $\mathrm{Y}, \mathrm{Wu} \mathrm{Y}$, Chen J, Zhao S, Li H. Pirfenidone attenuates cardiac fibrosis in a mouse model of TAC-induced left ventricular remodeling by suppressing NLRP3 inflammasome formation. Cardiology. (2013) 126:111. doi: $10.1159 / 000351179$

16. Qin W, Liu B, Yi M, Li L, Tang Y, Wu B, et al. Antifibrotic agent pirfenidone protects against development of radiation-induced pulmonary fibrosis in a murine model. Radiat Res. (2018) 190:396-403. doi: 10.1667/RR15017.1

17. Conte E, Gili E, Fagone E, Fruciano M, Iemmolo M, Vancheri C. Effect of pirfenidone on proliferation, TGF-beta-induced myofibroblast differentiation and fibrogenic activity of primary human lung fibroblasts. Eur J Pharmac. (2014) 58:13-9. doi: 10.1016/j.ejps.2014.02.014

18. Li G, Ren J, Hu Q, Deng Y, Chen G, Guo K, et al. Oral pirfenidone protects against fibrosis by inhibiting fibroblast proliferation and TGF-beta signaling in a murine colitis model. Biochem Pharmacol. (2016) 117:5767. doi: 10.1016/j.bcp.2016.08.002

19. Iyer SN, Hyde DM, Giri SN. Anti-inflammatory effect of pirfenidone in the bleomycin-hamster model of lung inflammation. Inflammation. (2000) 24:477-91. doi: 10.1023/a:10070683 13370

20. Iyer SN, Wild JS, Schiedt MJ, Hyde DM, Margolin SB, Giri SN. Dietary intake of pirfenidone ameliorates bleomycin-induced lung fibrosis in hamsters. J Lab Clin Med. (1995) 125:779-85.

21. Card JW, Racz WJ, Brien JF, Margolin SB, Massey TE. Differential effects of pirfenidone on acute pulmonary injury and ensuing fibrosis in the hamster model of amiodarone-induced pulmonary toxicity. Toxicol Sci. (2003) 75:16980. doi: $10.1093 /$ toxsci $/ \mathrm{kfg} 167$

22. Al-Bayati MA, Xie Y, Mohr FC, Margolin SB, Giri SN. Effect of pirfenidone against vanadate-induced kidney fibrosis in rats. Biochem Pharmacol. (2002) 64:517-25. doi: 10.1016/s0006-2952(02)0 1213-3

23. Misra HP, Rabideau C. Pirfenidone inhibits NADPH-dependent microsomal lipid peroxidation and scavenges hydroxyl radicals. Mol Cell Biochem. (2000) 204:119-26. doi: 10.1023/a:1007023532508

24. Giri SN, Leonard S, Shi X, Margolin SB, Vallyathan V. Effects of pirfenidone on the generation of reactive oxygen species in vitro. J Environ Pathol Toxicol Oncol. (1999) 18:169-77

25. Shihab FS, Bennett WM, Yi H, Andoh TF. Effect of pirfenidone on apoptosisregulatory genes in chronic cyclosporine nephrotoxicity. Transplantation. (2005) 79:419-26. doi: 10.1097/01.tp.0000151721.99418.48

26. Chen K, Chen L, Ouyang Y, Zhang L, Li X, Li L, et al. Pirfenidone attenuates homocysteineinduced apoptosis by regulating the connexin 43 pathway in H9C2 cells. Int J Mol Med. (2020) 45:1081-90. doi: 10.3892/ijmm.2020. 449710.3892/ijmm.2020.4497

27. Li C, Han R, Kang L, Wang J, Gao Y, Li Y, et al. Pirfenidone controls the feedback loop of the AT1R/p38 MAPK/renin-angiotensin system axis by regulating liver $\mathrm{X}$ receptor-alpha in myocardial infarction-induced cardiac fibrosis. Sci Rep. (2017) 7:40523. doi: 10.1038/srep40523

28. Sun P, Lu X, Xu C, Wang Y, Sun W, Xi J. CD-sACE2 inclusion compounds: an effective treatment for corona virus disease 2019 (COVID-19). J Med Virol. (2020) 92:1721-3. doi: 10.1002/jmv.25804

Conflict of Interest: The authors declare that the research was conducted in the absence of any commercial or financial relationships that could be construed as a potential conflict of interest.

Copyright (c) 2021 Seifirad and Alquran. This is an open-access article distributed under the terms of the Creative Commons Attribution License (CC BY). The use, distribution or reproduction in other forums is permitted, provided the original author(s) and the copyright owner(s) are credited and that the original publication in this journal is cited, in accordance with accepted academic practice. No use, distribution or reproduction is permitted which does not comply with these terms. 